\title{
20 AÑOS emprendidos desde cero
}

\section{Pro. Leopoldo Peláez A.}

Presidente Consejo Superior

Universidad Autónoma de Manizales

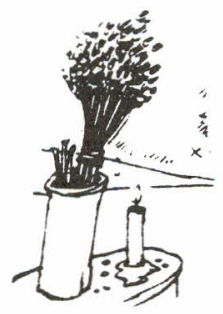

s ésta una celebración muy especial. Son veinte años de fundación. Por fuerza de la vida tengo yo el honor, la alegría y el deber de ser galardonado con la medalla "GUILLERMO OCAMPO AVENDAÑO» recién estatuida para quienes se hayan destacado en el aprecio, el tesón y la tarea de llevar adelante la Universidad y de impulsarla y hacerla brillar con decidida luz en el horizonte de la Patria.

He aceptado con orgullo esta presea porque señala y representa no propiamente mis merecimientos, sino porque entraña de verdad la fuerza de esta raza. Hace poco -seis meses nada más- escuchabamos en este mismo recinto las palabras emocionadas de Guillermo Ocampo Avendaño en cuyo honor se instituyó, la epopeya de su travesía por el tiempo y el espacio de esta querida ciudad.

En un acto sublime de fe en Dios y en este su pueblo -Pueblo de Dios también- Guillermo trazaba con verbo fulgurante y traído dulcemente en las palabras de su hija, una memoria incomparable de 


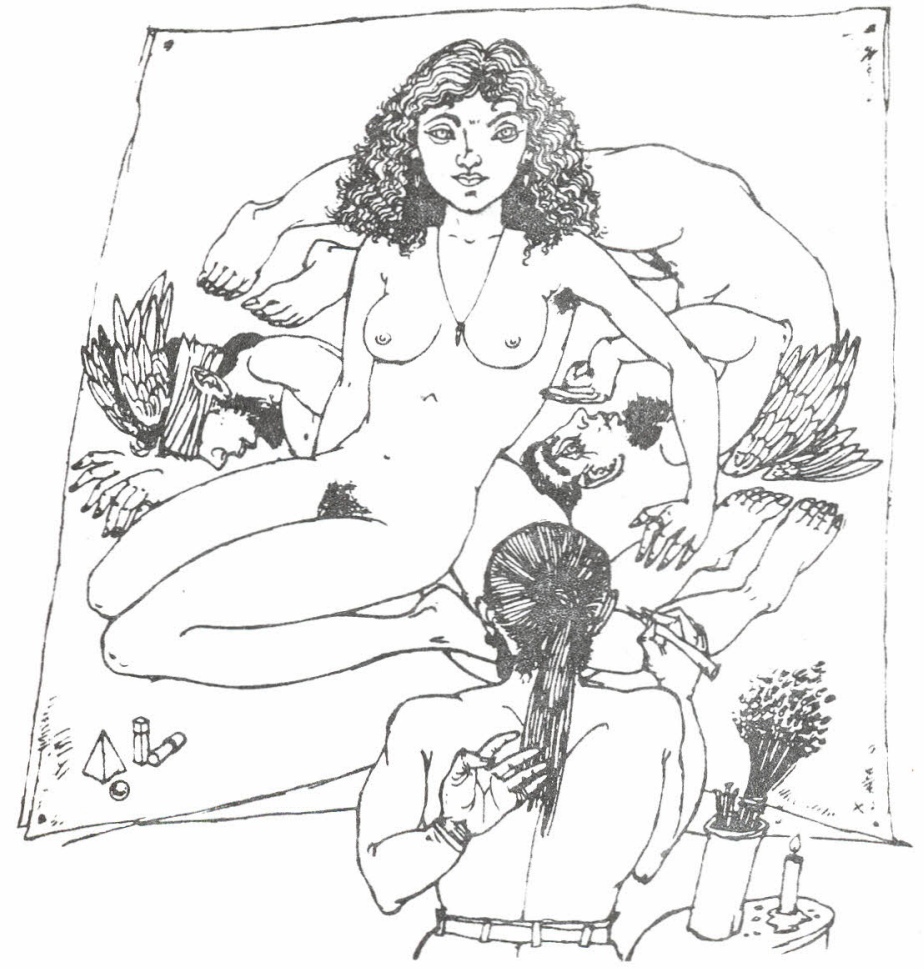

su «Parábola Fundacional» realizada en Caldas para Colombia y que concluye precisamente en este meridiano de luz que es la queridísima Universidad Autónoma de Manizales, verdadero objeto hoy de esta distinción.

Y... es esta la razón de mi contento: no es mi mérito, ni mi obra, ni mi esfuerzo. Es la tarea cumplida por hombres y mujeres de este suelo raizal que una vez más se luce con su obra.

Es el fruto ya maduro de la fe que éstos han sabido poner con amor y esperanza en la única realidad que iguala a los hombres en el mundo: LA EDUCACION. Destaca justamente ésta en la bellísima fantasía hecha madera del maestro Guillermo Botero en el teatro Los Fundadores como presagio, emblema y paradigma de Manizales y de Caldas: una «e» de LA EDUCACION. Es ésta la que deberíamos estar galardonando con la Medalla que se torna luz para animar este momento difícil de la Patria.

Con motivo del reciente paro que le sumó amarguras a mi gente, el Señor Ministro en declaraciones a la prensa dejó también plasmada esta idea que-quiero recoger para alimentar la esperanza de la que tenemos que saber dar cuenta los cristianos.

Veinte años de educación superior emprendidos desde cero, con el empuje inefable de Silvio Botero de los Ríos muerto en olor de reciedumbre y honradez.

Veinte años de posición aguerrida y voz de trueno de Fabio Trujillo Agudelo desafiante frente a dificultades y angustias como Presidente del Consejo Superior por muchos años.

Veinte años servidos a los jóvenes de nuestra tierra con la franciscana serenidad de Ernesto Gutiérrez A. nuestro rector fundador.

Veinte años casi plenos en los cuales Ignacio Restrepo Abondado entregó lo mejor de sí y de su estirpe a esta lucha sin tregua. En su pecho debiera brillar esta medalla -que no en el mío- pero en la vida hay paradojas indescifrables, $¡$ Dios sea bendito!

Veinte años de labores constantes con Gabriel Arango Restrepo, Don Gustavo Larrea Cordova y otros.

Veinte años de presencia en la torre «Emblema de la Autónoma» porque Hernán Jaramillo J. con su carácter duro hace sonar la emisora donada por su familia y el reloj que sus propias manos arreglaron.

Veinte años de lucha en manos de Guillermo Ocampo Avendaño quien también hoy cumple la brega, no obstante sus límites, imponiendo la Medalla que lleva su nombre.

Veinte años de los cuales éste último ha sabido vadear Humberto Montoya Jaramillo nuestro Rector, en medio de tormentas. Dios lo siga llevando a buen puerto: 
Veinte años de clases, talleres. laboratorios, ideas, realizaciones, grados, horas de oficina, biblioteca. festejos, consejos, academia finanzas, bienestar, oraciones y más, en los cuales empleados, profesores, estudiantes, directivos, padres de familia, personas de apoyo en el servicio, han dejado la esencia misma de sus personas en la página gloriosa de esta historia.

Veinte años en que también están cosidos a la misma tarea $\mathrm{Al}$ caldes y Concejos de la ciudad que con su apoyo y con su orientación han hecho del sitio histórico de la Estación - La Estación de la EDUCACION y la cultura de Manizales.

Veinte años tejidos con el amor de Elvira, Olga, Gloria, Luz y tantos otros que ofrendan permanentemente sus delicadezas a padres. estudiantes y empleados.

Veinte años de producto terminado, que son los egresados, con el esmero y la firmeza de Decanos, Secretarias y Trabajadores que sin cesar han abonado su campo

Veinte años de «Dios con nosotros» dispensádonos amor, gozo y ternura en LA EDUCACION de hombres y mujeres aptos y dignos para la tarea humana que corresponde a esta época amarga y dura.
La Universıdad que necesitamos dice Federico Mayor Zaragoza es aquella que se proponga hacer de cada inteligencia una conciencia. Un compromiso personal con la sociedad en la que se arraiga y en la que sirve.

Tenemos que mirar hacia adelante con el optimismo de quien está bien plantado en su realidad.

La misión de la Universidad puede resumirse así: enseñar, enseñar a enseñar, investigar y enseñar a investigar

La Universidad debe bajar a la arena de este mundo sobrecogido y turbado y decir que todavía estamos a tiempo de cambiar tanta tribulación en ESPERAN-
Que la voz de la Universidad se haga oir a través de los universita- rios portadores de la mayor riqueza de todos los pueblos.

ZA. Salgamos como universitarios y proclamemos a los cuatro vientos la urgente necesidad de un cambio radical de rumbo para que la nave de nuestros pueblos nuestro país- enfile su rumbo hacia la paz y no hacia la guerra, hacia la plena realización de todos los hombres y no hacia los intereses de unos cuantos. Entre las responsabilidades de las universidades y de sus miembros, directivas, profesores y alumnos está muy en primer término su contribución a la comprensión, a la tolerancia, al respeto mutuo y a la justicia social, de todo lo cual depende el futuro de nuestra sociedad. Y es preciso que esa contribución sea visible.

«Luzca así vuestra luz ante los hombres, para que vean vuestras buenas obras y glorifiquen al padre», dice el Evangelio de Jesus.

Que la voz de la Universidad se haga oir a través de los universitarios portadores de la mayor riqueza de todos los pueblos. De su tenacidad y su coraje dependen hoy aspectos esenciales para el futuro de la humanidad.

Palabras en los 20 años de la Universidad Autónoma de Manizales, con motivo de recibir la Medalla "Guillermo Ocampo Avendaño». 